\title{
Nurse Handover and Its Implication on Nursing Care in the University of Calabar Teaching Hospital, Calabar, Nigeria
}

\author{
Alberta David $\mathrm{N}^{*}$, Idang Neji $\mathrm{O}$ and Jane E
}

\author{
Department of Nursing Science, University of Calabar, Cross \\ River State, Nigeria.
}

"Correspondence:

Alberta Davi N, Department of Nursing Science, University of Calabar, Cross River State, Nigeria. Tel: +2347031931751, E-mail: albertansemo@yahoo.com.

Received: 04 June 2018; Accepted: 28 June 2018

Citation: Alberta David N, Idang Neji O, Jane E. Nurse Handover and Its Implication on Nursing Care in the University of Calabar Teaching Hospital, Calabar, Nigeria. Nur Primary Care. 2018; 2(3): 1-9.

\begin{abstract}
Background: The study examined Nurses handover and its implication for nursing care in University of Calabar Teaching Hospital (UCTH), Calabar. Nurse handover is a report given when the nursing professional transfers the responsibility for the patients and what has been done in his/her shift to another that is arriving.

Objectives: The following objectives guided the study; to examine the various aspects of nurse handover, identify the methods practiced in UCTH, Calabar; identify the factors influencing Nurses handover and examine its implications on patients' care in the UCTH, Calabar. Also to test for a significant relationship between nurse handover and patients care in UCTH.

Method: The study employed a descriptive survey design using a sample size of 85 respondent selected purposively. A well-structured questionnaire was used to elicit information from the respondents after ascertaining the reliability of the instrument. Data collected was analysed using SPSS 21.0 statistical packages while the hypothesis was tested using the Pearson Product Moment Correlation Coefficient at 0.05 level of significance. The Nursing Need Theory developed by Virginia Henderson in 1966 directed the study.

Results: Findings from the study revealed transfer of information from one shift to the other as an important aspect of nurse handover 71(83.5\%) among others; report writing and bedside verbal handover as the methods of nurse handover very often practiced in the UCTH, Calabar 85(100\%); Report content, attitude of the nurses, nurse experience, lateness to work, workload and stress, and interpersonal conflicts were identified as influences on nurse handover. The study further revealed that nurse handover enhances nurses and patients /family relationship, improves communication, nurse performance and clinical outcome. A significant positive relationship between nurse handover and patient care was also revealed. However, the study findings highlighted that bedside verbal handover restricts the sharing of vital information concerning patient condition.
\end{abstract}

Conclusion: The study concluded that the nurse handover is a key moment for guaranteeing the continuity of care and the patients' safety. Hence the study recommends the need for inclusion of nurse handover in the training curriculum of nursing students, regular updates among practicing nurses to enable them acquire special skills that will improve handover content and communication during handover process, among others.

\section{Keywords}

Nurses handover, Implication for nursing care, Practicing nurses, Nursing students.

\section{Introduction}

Nurse handover has always been a vital element of the nursing care process, and communication is a core element in this process especially during the transfer of information. The passage of time and introduction of scientific and technological advances, has led to a new focus on the delivery of information with quality and timeliness. The nurses' shift change or handover is a report given when the nursing professional transfers the responsibility for the 
patients and what has been done in his/her shift to another that is arriving [1]. According to [2], the transfer of this essential information and responsibility for care of the patient from one nurse on duty to another, is an integral component of communication system in nursing care practice which supports the transition of critical information and continuity of care and treatment.

The nurse handover is complex and includes communication between the change of shift, communication between care providers about patient care, handover, records, and information tools to assist in patient care. It is also "a mechanism for transferring information, primary responsibility, and authority from one or a set of caregivers, to oncoming staff' [3]. So, conceptually, the nurse handover process must provide critical information about the patient, include communication methods between sender and receiver, transfer responsibility for care, and be performed within complex organizational systems and cultures that impact patient safety [3]. Accordingly, the complexity and nature of the type of information, communication methods, and various caregivers for each of these factors impact the effectiveness and efficiency of the nurse handover as well as patient safety [3]. As argued by [4], nurse handover is very significant to nursing practice as it offers nurses opportunity to weigh the benefit and responsibilities of sharing the information that is in their hands with others. Based on this, the authors concluded that as defenders of patient and professional privacy, nursing professionals should be clear on the intentions of sharing facts and opinions and, similarly, determining the manner of management of relevant, confidential information for the patient's care. This implies value judgments concerning what are important for his/her care and what they are authorized to share and under what circumstances. Similarly, it implies discerning what information to divulge within the context of the collegial relationship and what teamwork requires.

\section{Statement of the problem}

An accurate handover of clinical information is of great importance to continuity of care and patient safety [2]. If clinical information is not shared accurately and in timely manner it may lead to delay in treatment and diagnosis. Certain factors have been identified that influence the nurse handover such as; distractions, including parallel conversations, the movement of carts and supplies, clothes and food, cleaning machines, the high volume of radios and televisions, telephone calls, interruptions by medical and support staff, and conversations in the corridor and nursing center situations that are more common during shift changes in the morning and the afternoon, given that they are hours of greater circulation. Incomplete information, distractions, and errors in communication during the nurse handover are the principal causes of adverse events, such as medication errors, prolonged hospital stays with unnecessary diagnostic tests, and patient dissatisfaction.

In the University of Calabar Teaching Hospital, it was observed that nurse handover at almost every change of shift generated discrepancies and disagreement among nurses. This conduct provokes personnel actions that do not contribute to a good process and becomes a vicious cycle that impacts the handover itself, given that it generates negative responses that do not contribute to the continuity and professional critical judgment for prioritizing and organizing care. These aroused the curiosity of the researchers to seek answers to the following questions; what are the various methods of handover common to nurses in UCTH, Calabar? What factors impact on proper nurse handover in UCTH, Calabar and how does this implicate care in UCTH, Calabar. A null hypothesis; there is no positive relationship between nurses handover and patient care in UCTH, was also formulated and tested.

\section{Research Setting}

The study was conducted in University of Calabar Teaching Hospital (UCTH), a tertiary health care facility located in Calabar Municipality of Cross River State, Nigeria. The hospital serves as a clinical setting for teaching medical, nursing, medical laboratory science, radiography students, and also students from other health related courses. It also provides specialist clinical services as well as promotion of scientific knowledge through research. The hospital is also made up of twenty-five (25) wards and units with 257 nursing staff.

\section{Literature review}

\section{Concept of nurse handover}

Nurse handover is defined by [1], as the reports with the objective of relating what occurred and what care was given to a patient during the previous shift, for the next shift's members to know the fundamental aspects of the patients' present condition, in an effort to guarantee continuity of care. The report could be understood as a complex and important part of the professional practice that attends to various objectives, including communication, the supply of current information, and the continuity and quality of the patients' care, as well as the assignment of responsibilities and routine duties. In view of this, it serves as an important process of information exchange to secure and maintain the continuity and quality of attention in favor of the patients' safety, which happens within legal regulations of the professional practice. According to [6], the importance of the nurse handover in the process of caring for patients has motivated the development of protocols to standardize the process in different health institutions, even though the literature shows that the results obtained are not satisfactory. In the majority of health institutions, there are protocols and guides for the shift change, which are defined as activities that guarantee the patient's continuity of care by nursing personnel and attendance to elements necessary for patient care, such as a service inventory or a report of any change that has occurred [6]. Simultaneously, it is described more explicitly as a procedure through which one receives a report on each one of the patients that includes diagnosis, evolution, treatment, activities, and completed and pending examinations [2]. A handover report should be formulated as a method of providing relevant information to orient daily practice and direct care. The report should, therefore, be informative and educative for the nurses, patients, and their families. It should convey not only details about the patient's state and treatment but also care plans [7].

However, [8] observed that one of the main difficulties is the 
fact that the report often lacks form or structure; therefore, the information that it transmits is irrelevant, repetitive, and speculative, jeopardizing the process in some cases due to lack of directives. In line with this, (9) also noted that flaws in this process interfere with continuity of care and that the spaces and time frames for completing the report vary from one institution to another.

\section{Characteristics of nurse handover process}

As stated by [3], the handover process is characterized as being a routine, daily event that is performed in the morning, in the afternoon, and at night. Staying within the assigned time is one of the reoccurring challenges for nursing professionals, with an average time for shift changes ranging between 15 to 45 minutes, depending on the number and condition of the patients. Emphases have been placed on the complexity of the shift report and difficulties associated with it, such as the lack of communication and inadequate transfer of care $[10,11]$.

According to [12], in the nurse handover process, information about the patients' physical, psychosocial, and spiritual aspects, as well as medical facts, opinions, and impressions, are shared to resolve care problems, to give and receive help, to construct relationships, and to manage conflicts. The report should be sufficiently broad to be holistic in nature and to consider the patient's long-term care objectives, but it should also be sufficiently specific to meet short-term goals and to offer individual preferences for satisfying the patient's needs and not the needs of the nursing professionals $[11,12]$. Therefore, the nurse handover signifies a time for communication to promote care, safety, and best practices with the aim of eliminating risks to the patient [12]. Additionally, personal significance and socialization can be an objective or personal goal for welcoming patients and their families during the handover because the shift report may have an emotional significance. An example of this is the nurses' participation in the difficulties and anxieties in this time of care, which is understood as a time or space for interrelation among the nursing staff, the patients, and the patients' families to generate, give, and strengthen the nursing care [12].

In this way, the handover becomes a time to connect with the patient, his/her family, and the rest of the staff to resolve difficulties that have occurred in the course of the shift with the entire team and, simultaneously, to socialize, sharing what was resolved and what is pending [13]. Similarly, nursing stations, conference rooms, patients' headboards, and hallways are the places where the shift report is carried out [13]. The most common forms are the oral and written report, followed by the recording, which has the disadvantage of zero feedback, and, finally, one with the patient [14]. In that form, the patient is included and welcomed into the report given to the entering nurse; the literature agrees that this is the best way to complete the shift report, especially for the night shift [14].

Barriers in the Transfer of Information

A systematic literature review by [15], identified barriers to the adequate transfer of information, which they classified into eight categories: communication barriers, problems with standardization or policies that ensure the process, difficulties with technical equipment, difficulties with the complexity and number of patients, the training and education of personnel, and human factors. Despite the known negative consequences of inadequate transfers of information, very little investigation has been conducted to identify best practices [15]. There is a notable coherence in the suggested strategies, but there is a lack of evidence to support them [15].

As posit by [16], the traditional methods tend to be long, incoherent, and incorrect regarding the patient's information; the content sometimes deviates to irrelevant declarations or a priori judgments that carry negative prejudices from the professionals toward the patients. In this way, one can convert the report into a vehicle for disrespect, lack of communication, unconscious negativity, and projections that can weaken interpersonal relationships and ethical values [16].

Another factor that can influence the handover are distractions, including parallel conversations, the movement of carts and supplies, clothes and food, cleaning machines, the high volume of radios and televisions, telephone calls, interruptions by medical and support staff, and conversations in the corridor and nursing center situations that are more common during shift changes in the morning and the afternoon, given that they are hours of greater circulation [17]. Hence according to [17], incomplete information, distractions, and errors in communication during the nurse handover process are the principal causes of adverse events, such as medication errors, prolonged hospital stays with unnecessary diagnostic tests, and patient dissatisfaction. This conduct provokes personnel actions that do not contribute to a good process but impacts the handover itself, given that it generates negative responses that do not contribute to the continuity and professional critical judgment for prioritizing and organizing care $[16,17]$.

The ethics of nurse handover

Discussing the ethics in care is an important and frequently referenced point in the literature. Indeed, it is one of the principal duties of nurses to weigh the benefit and responsibilities of sharing the information that is in their hands with others [2]. As defenders of patient and professional privacy, nursing professionals should be clear on the intentions of sharing facts and opinions and, similarly, determining the manner of management of relevant, confidential information for the patient's care [2]. This implies discerning what information to divulge within the context of the collegial relationship and what teamwork requires [2].

Nursing professionals' information management and decisionmaking should be based on principles associated with fairness, respect, dignity, and commitment and not necessarily on their own needs or society's needs [2]. Indeed, moral considerations change with time because the level of reasoning changes, resulting in cognitive maturity, practical experience, formal education, and the environments. In addition, it is expected that nurses 
adhere to values of the professional practices, ethical codes, a scheme of principles that demonstrates the profession's members' responsibility to society [8]. The Code of Ethics for Colombia summarizes nurses' values and rights to follow for making ethical decisions and providing high-quality nursing care [8]. With this understanding, the shift report should be seen as a vehicle for sharing values, beliefs, perceptions, judgments, and above all, respect [8]. When a shift change is established in a manner founded in ethics, responsibility, and the quality and safety of care, relationships are improved, the efficiency and functioning of teamwork are strengthened, time is optimized, and incorrect or insufficient information is not passed on [18].

Importance of patient and family participation in nurse handover process

Evidently, the process has not traditionally included patients and their families, as families have often been required to leave the room during the procedure. Findings from a study by [19] demonstrated that nursing professionals see completing the shift report with patients as a serious problem because it may lengthen rather than shorten the time in the event of asking questions due to interaction with them and family. However, nursing professionals do not realize that those same patients and their families are administrators of their own care in a hospital stay, and they are not given the opportunity to listen to and participate in the exchange of information [19]. Similarly, the sharing of information between shifts is encouraged by means of the patient's direct observation of both nurses rather than generating assumptions; when the report is not completed with the patient, the opportunity to include the patient and family in planning care is lost [20]. Despite the anxieties concerning the implementation of the shift report with the patient, there are studies that demonstrate the benefits of this process [21]. One benefit is the nurse's ability to confirm the information immediately by viewing the patient and obtaining a baseline assessment to compare changes during the shift, thus planning and prioritizing the patient's care [21].

Evidence suggests that patients who are better informed are less anxious, more adherent to their care, more autonomous in their treatment goals, so feel satisfied [11]. Additionally, the benefits of carrying out the handover with the patient include not only taking the patient into consideration with a more holistic and prioritized care but also greater professional satisfaction, which encourages teamwork across all shifts, promoting personal responsibility and universal commitment [11].

\section{Nurse Handover in patients care}

A study conducted by [22], on Standardized Shift Handover Protocol: Improving Nurses' Safe Practice in Intensive Care Units, states that for maintaining the continuity of care and improving the quality of care, effective inter-shift information communication is necessary, hence concluded that using a standard handover protocol for communicating patient's needs and information improves nurses' safe practice in the area of basic nursing care. A study on the role of the nurse-to-nurse handover in patient care by [17], concludes that the nurse-to-nurse handover is not taught formally during training, yet it is one of the most important rituals of the nursing shift. A study by [5] to examine communication in verbal hand-over reports revealed that the handover verbal communication experienced between the nurses had many advantages which can be connected with nurses' satisfaction in providing high quality care and that this reflects positively in patient's satisfaction and safety. Similarly, [18] conducted a qualitative research on Challenges of Nursing Handover with the aim of exploring the challenges of nursing handover process during shift rotation in hospitals. The study suggested applying a holistic approach in managing handover situations to overcome handover challenges [18].

\section{Factors influencing Nurse Handover}

In a study on factors that impact on the safety of patient handovers, [23] argues that improvement of clinical handover is fundamental to meet the challenges of patient safety, with the aim of exploring healthcare professionals' attitudes and experiences with critical episodes in patient handover, in order to elucidate factors that impact on handover from ambulance to hospitals and within and between hospitals. They found eight central factors to have an impact on patient safety in handover situations: communication, information, organisation, infrastructure, professionalism, responsibility, team awareness, and culture [23]. Also, Study by [24], to examine factors affecting professional handing over ethics in nursing practice in Iran, concluded that awareness of professional handing over ethics and its contributing factors could help nurses and healthcare professionals provide better services for patients. At the same time, such understanding would be valuable for educational administrators for effective planning and management.

\section{The implication of nurse handover in Nursing Care}

Evidence-based shift report tool was used by [25] to improve nurses' communication; the initiative outcomes showed decreased frequency of missed information. Likewise, another initiative implemented to translate an evidence -based protocol for nurse to nurse shift handover recommended that standardization related to transfer of information in the clinical practice is an essential aspect of patient safety and improves clinical outcomes [26]. The study was conducted in the Intensive Care Unit (ICU), in 2011, on one group pre-test -post-test quasi-experimental study, the study population consisted of all ICU nurses affiliated with a large scale teaching hospital located in Mashhad -Iran, data was collected using a shift handover evaluation checklist. As the main purpose of the study was to change the nurses shift handover behavior, the use of Lewin's change theory was followed to implement behavioral or cultural changes. Study findings showed that post implementation of the designed shift handover protocol, the nurse's performance improved in terms of patient safety through updating their caring program, maintaining the continuity of care, and improving the quality $[25,27]$.

A study on bringing change-of-shift report to the bedside: a patient- and family-centered approach, [2] observed that Nursing shift handovers was considered to be a pattern of communication 
that is applied in everyday clinical nursing practice, in order to fulfilled the goals of organization, continuity, consistency and safety of care that nurses provide to patients. The study thus concluded that effective communication practices among nurses entail effective handovers, effective patient care quality and patient safety maintenance [2].

\section{Methodology}

The study employed descriptive survey design, which was chosen to enable the researcher depict the respondents in an accurate way and also assess relevant information where necessary. A total of 257 nurses and midwives work in the sixteen [16] wards of UCTH, out of which eight (8) wards were randomly selected. Taro Yomane's formula was used to determine the sample size of 85 practicing nurses and midwives for the study which were selected using purposive sampling technique. Nurses and midwives on morning and afternoon duties were selected because that was when majority of them were available. Practicing nurses and midwives within the ranks of Nursing Officers 11 to Chief Nursing Officers were included in the study. Data collection was done using a wellstructured questionnaire to elicit information from the respondents. The instrument was divided into four (4) sections; Section A comprised of personal data while section B, C,D and E contains items structured to elicit needed responses from respondents on aspects of nurse handover, methods of handover common to nurses in UCTH, factors that impact on proper nurse handover, and implications on patient care. The responses were made on a four (4) points linkert scale with scores ranging from four to one (4 to 1) on Strongly Agree (SA), Agree (A), Disagree (D), Strongly disagree (SD) respectively for positive worded items and vice versa for negative items. The researcher personally administered the questionnaire to the respondents.

Data collected for the study was analyzed using SPSS 21.0 statistical packages, and presented in simple percentages on frequency tables, while the hypotheses was tested using the Pearson Product Moment Correlation Coefficient at a level of 0.05 significance. Permission for the study was obtained from the Management of UCTH, Calabar, the respondents were adequately informed about the study and its objectives, and their consent was obtained. They were assured of anonymity and confidentiality throughout the study.

\section{Results}

The results of the data analyses were presented based on the research questions of the study.

Table 1 presents the results of socio-demographic data. The results showed that none of the respondents were between 18-24 years; $37(43.52 \%)$ respondents were between $25-31$ years; 26 (30.58\%) respondents were between 32-38 years; while the remaining 22 $(25.88 \%)$ respondents were between 39 years above years. 5 $(5.89 \%)$ were males, while $80(94.1 \%)$ were females. The result further revealed that out of 85 respondents that were sampled, $52(61.17 \%)$ were holders of Registered Nurses and midwives certificate; 28 (32.94\%) were holders of bachelor of nursing science degree (BNSc.), while the remaining 5 (5.88\%) respondents had other professional qualifications. 34 (40.05) respondents were Nursing Officer I; 12 (14.11\%) were Nursing Officer II; 13 (15.295) were Senior Nursing Officers; 17 (20.0\%) were Principal Nursing Officers; 6 (7.05\%) Assistant Chief Nursing Officers while the remaining $3(3.53 \%)$ were Chief Nursing Officers. From the 85 respondent that participated in the study, $26(30.58 \%)$ respondents had served for $1-5$ years; $14(16.47 \%)$ had put in $6-10$ years in service; $12(14.11 \%)$ were $11-15$ years in service; $7(8.2 \%)$ had served for 16-20 years; 16 (18.82\%) had served for 21-25 years while the remaining $10(11.76 \%)$ had served 26 years and above (Table 1).

\begin{tabular}{|c|c|c|c|}
\hline \multicolumn{2}{|c|}{ Variable } & Frequency & Percentage \\
\hline \multirow{4}{*}{ Age } & $18-24$ years & - & - \\
\hline & $25-31$ years & 37 & 43.52 \\
\hline & $32-38$ years & 26 & 30.58 \\
\hline & 39 years and above. & 22 & 25.88 \\
\hline \multirow{2}{*}{ Gender } & Male & 5 & 5.89 \\
\hline & Female & 80 & 94.1 \\
\hline \multirow{3}{*}{$\begin{array}{l}\text { Professional } \\
\text { Qualification }\end{array}$} & $\mathrm{RN} / \mathrm{RM}$ & 52 & 61.17 \\
\hline & B.N.SC & 28 & 32.94 \\
\hline & Others & 5 & 5.88 \\
\hline \multirow{6}{*}{ Rank } & No II & 34 & 40.0 \\
\hline & NO I & 12 & 14.11 \\
\hline & SNO & 13 & 15.29 \\
\hline & $\mathrm{PNO}$ & 17 & 20.0 \\
\hline & ACNO & 6 & 7.05 \\
\hline & $\mathrm{CNO}$ & 3 & 3.53 \\
\hline \multirow{6}{*}{ Years of service } & $1-5$ & 26 & 30.58 \\
\hline & $6-10$ & 14 & 16.47 \\
\hline & $11-15$ & 12 & 14.11 \\
\hline & $16-20$ & 7 & 8.2 \\
\hline & $21-25$ & 16 & 18.82 \\
\hline & 26 years and above & 10 & 11.76 \\
\hline
\end{tabular}

Table 1: Showing Socio-demographic Data of Respondents.

Table 2 which present the aspects of nurse handover, shows that 38 $(44.70 \%)$ respondents strongly agreed that transfer of information from one shift to the other is an important aspect of nurse handover; $33(38.8 \%)$ agreed; $10(11.76 \%)$ disagreed; while the remaining $2(2.3 \%)$ strongly disagreed. $39(45.9 \%)$ respondents strongly agreed that report writing gives details of the health condition of each patients in the handover process; $36(42.4 \%)$ agreed; 6 (7.1\%) disagreed; while the remaining4 (4.7\%) strongly disagreed. 42 (49.4\%) respondents strongly agreed that verbal handover helps the nurses to exchange relevant information about patients care; 32 (37.6\%) agreed; 6 (7.0\%) disagreed; while the remaining $5(5.9 \%)$ strongly disagreed. Furthermore, 33 (38.8\%) respondents strongly agreed that bedside nurse handover does not permit sharing of vital information concerning the patients' condition; 31 (36.5\%) agreed; 10 (11.8\%) disagreed; while the remaining 11 (12.9\%) strongly disagreed. $34(40.0 \%)$ respondents strongly agreed that 
tape recorded handover reduces duration of handover process and does not allow interruption; 28 (32.9\%) agreed; 10 (11.8\%) disagreed while the remaining $13(15.9 \%)$ strongly disagreed. The result further revealed that $72(84.70 \%)$ respondents strongly agreed that nursing care plan is a critical aspect of nurse handover; $13(15.29 \%)$ agreed; but none of the respondents disagreed or strongly disagreed (Table 2).

\begin{tabular}{|c|c|c|c|c|c|c|}
\hline \multirow{2}{*}{ Statement } & \multicolumn{5}{|c|}{ Responses } & \multirow{2}{*}{ Total } \\
\hline & & SA & $\mathbf{A}$ & D & SD & \\
\hline \multirow{2}{*}{$\begin{array}{l}\text { Transfer of information from one } \\
\text { shift to the other is an important } \\
\text { aspect of nurse handover }\end{array}$} & Freq & 38 & 33 & 10 & 2 & 85 \\
\hline & $\%$ & 44.70 & 38.8 & 11.76 & 2.3 & 100.0 \\
\hline \multirow{2}{*}{$\begin{array}{l}\text { Report writing gives details of the } \\
\text { health condition of each patients } \\
\text { in the handover process }\end{array}$} & Freq & 39 & 36 & 6 & 4 & 85 \\
\hline & $\%$ & 45.9 & 42.4 & 7.1 & 4.7 & 100.0 \\
\hline \multirow{2}{*}{$\begin{array}{c}\text { Verbal handover helps the nurses } \\
\text { to exchange relevant information } \\
\text { about patients care }\end{array}$} & Freq & 42 & 32 & 6 & 5 & 85 \\
\hline & $\%$ & 49.4 & 37.6 & 7.0 & 5.9 & 100.0 \\
\hline \multirow{2}{*}{$\begin{array}{l}\text { Bedside nurse handover does } \\
\text { not permit sharing of vital } \\
\text { information concerning the } \\
\text { patients condition }\end{array}$} & Freq & 33 & 31 & 10 & 11 & 85 \\
\hline & $\%$ & 38.8 & 36.5 & 11.8 & 12.9 & 100.0 \\
\hline \multirow{2}{*}{$\begin{array}{l}\text { Tape recorded handover reduces } \\
\text { duration of handover process and } \\
\text { does not allow interruption }\end{array}$} & Freq & 34 & 28 & 10 & 13 & 85 \\
\hline & $\%$ & 40.0 & 32.9 & 11.8 & 15.29 & 100.0 \\
\hline \multirow{2}{*}{$\begin{array}{l}\text { Nursing care plan is a critical } \\
\text { aspect of nurse handover }\end{array}$} & Freq & 72 & 13 & - & - & 85 \\
\hline & $\%$ & 84.70 & 15.29 & - & - & 100 \\
\hline
\end{tabular}

Table 2: Showing Aspects of Nurse handover.

(Positive Responses = summation of Strongly agree SA \& Agree A, Negative Responses = summation of Disagree D \& Strongly disagree SA).

Table 3 presents methods of nurse handover practiced in UCTH. Result reveals that report writing and bed side verbal hand over, were nurse handover methods practiced very often in the UCTH, Calabar 85 (100\%). Compound report is used often; medication and observation charts used as a method of nurse handover rarely, clinical meetings practiced but very rarely, while audio tape recording is never practiced in UCTH, Calabar (Table 3).

\begin{tabular}{|c|c|c|c|c|c|c|}
\hline Variables & $\begin{array}{c}\text { Very } \\
\text { Often }\end{array}$ & Often & Rarely & $\begin{array}{c}\text { Very } \\
\text { Rarely }\end{array}$ & $\begin{array}{c}\text { Not } \\
\text { at all }\end{array}$ & $\begin{array}{c}\text { Total } \\
(\%)\end{array}$ \\
\hline Report writing & 85 & - & - & - & & $85(100)$ \\
\hline $\begin{array}{c}\text { Bed side verbal } \\
\text { handover }\end{array}$ & 85 & - & - & - & & $85(100)$ \\
\hline Compound Report & - & 85 & - & - & & $85(100)$ \\
\hline Clinical meetings & - & - & - & 85 & & $85(100)$ \\
\hline $\begin{array}{c}\text { Medication and } \\
\text { observation Chart }\end{array}$ & - & - & 85 & - & & $85(100)$ \\
\hline Audio Tape recording & - & - & - & - & 85 & $85(100)$ \\
\hline
\end{tabular}

Table 3: showing method of nurse handover practiced in UCTH, Calabar.

Table 4 shows factors affecting nurse handover in UCTH. From the results $38(44.7 \%)$ respondents strongly agreed that communication is a vital element in the handover process; 30 (35.3\%) agreed; 10 (11.8\%) disagreed; while 7 (8.2\%) respondents strongly disagreed. Twenty-five, 25 (29.4\%) respondents strongly agreed that handover process depends on the type of information available to the incoming nurse; $15(17.7 \%)$ respondents agreed; $24(28.2 \%)$ respondents disagreed; while 21 (24.7\%) respondents strongly disagreed. Also, $41(48.2 \%)$ respondents strongly agreed that the attitude of the nurses' can influence the effectiveness of handover; 39 (45.9\%) respondents agreed; 4 (4.7\%) disagreed; while $1(1.2 \%)$ respondents strongly disagreed. Furthermore, 37 $(43.5 \%)$ respondents strongly agreed that ethics of handover serve as fundamentals to meet patient safety challenges; $28(33.0 \%)$ respondents agreed; $11(12.9 \%)$ respondents disagreed; while 9 $(10.6 \%)$ respondents strongly disagreed. In addition, 19 (22.4\%) respondents strongly agreed that the nurse experience is an important factor in the handover process; 20 (23.5\%) respondents agreed; 29 (34.1\%) respondents disagreed; while 17 (20.0\%) respondents strongly disagreed. Lateness to work which causes rushing over the handover process was highlighted ass an influence $80(94.1 \%)$ strongly agreed, 5 (5.8\%) agreed. Other influences includes workload and stress $85(100 \%)$ and interpersonal conflicts between nurses 60 (70.5\%) strongly agreed (Table 4).

\begin{tabular}{|c|c|c|c|c|c|c|}
\hline \multirow{2}{*}{ Statement } & \multicolumn{5}{|c|}{ Responses } & \multirow{2}{*}{ Total } \\
\hline & & SA & $\mathbf{A}$ & D & SD & \\
\hline \multirow{2}{*}{$\begin{array}{l}\text { Communication is a vital element } \\
\text { in the handover process }\end{array}$} & Freq. & 38 & 30 & 10 & 7 & 85 \\
\hline & $\%$ & 44.7 & 35.3 & 11.8 & 8.2 & 100 \\
\hline \multirow{2}{*}{$\begin{array}{l}\text { Handover process depends on the } \\
\text { type of information available to the } \\
\text { incoming nurse (report content) }\end{array}$} & Freq. & 25 & 15 & 24 & 21 & 85 \\
\hline & $\%$ & 29.4 & 17.7 & 28.2 & 24.7 & 100 \\
\hline \multirow{2}{*}{$\begin{array}{l}\text { The attitude of the nurses' can } \\
\text { influence the effectiveness of } \\
\text { handover }\end{array}$} & Freq. & 41 & 39 & 4 & 1 & 85 \\
\hline & $\%$ & 48.2 & 45.9 & 4.7 & 1.2 & 100 \\
\hline \multirow{2}{*}{$\begin{array}{l}\text { Ethics of handover serve as } \\
\text { fundamentals to meet patient safety } \\
\text { challenges }\end{array}$} & Freq. & 37 & 28 & 11 & 9 & 85 \\
\hline & $\%$ & 43.5 & 33.0 & 12.9 & 10.6 & 100 \\
\hline \multirow{2}{*}{$\begin{array}{l}\text { The nurse experience is an } \\
\text { important factor in the handover } \\
\text { process }\end{array}$} & Freq. & 19 & 20 & 29 & 17 & 85 \\
\hline & $\%$ & 22.4 & 23.5 & 34.1 & 20.0 & 100 \\
\hline \multirow{2}{*}{$\begin{array}{l}\text { Lateness to work causes rushing } \\
\text { over handover processes }\end{array}$} & Freq. & 80 & 5 & - & - & 85 \\
\hline & $\%$ & 94.1 & 5.8 & & & 100 \\
\hline \multirow{2}{*}{$\begin{array}{c}\text { Short staffing/ workload and stress } \\
\text { exert influence on nurse handover } \\
\text { process }\end{array}$} & Freq. & 85 & - & - & - & 85 \\
\hline & $\%$ & 100 & - & - & - & 100 \\
\hline \multirow{2}{*}{$\begin{array}{l}\text { Interpersonal conflict between } \\
\text { colleague is challenging to nurse } \\
\text { handover process }\end{array}$} & Freq. & 60 & 10 & 10 & 5 & 85 \\
\hline & $\%$ & 70.5 & 11.7 & 11.7 & 5.8 & 100 \\
\hline
\end{tabular}

Table 4: Showing Factors influencing Nurses handover.

(Positive $=$ summation of Strongly agree $(\mathrm{SA}) \&$ Agree $(\mathrm{A})$, Negative $=$ summation of Disagree (D) \& Strongly disagree (SD).

Results in Table 5 which present the implication of nurse handover on patient care, revealed that $10(11.8 \%)$ respondents strongly agreed that handover enhance nurses' and patients' family relationship; 2 (4.7\%) respondents agreed; 33 (38.8\%) respondents disagreed; while $38(44.7 \%)$ respondents strongly disagreed. Six, $39(45.9 \%)$ respondents strongly agreed that handover helps nurses to improve patients safety; $36(42.4 \%)$ respondents agreed; $4(4.7 \%)$ respondents disagreed while the remaining $6(7.1 \%)$ respondents strongly disagreed. Furthermore, $42(49.4 \%)$ respondents strongly agreed that through handover 
nurses are able to improve their clinical outcomes; $32(37.6 \%)$ respondents agreed; $5(5.9 \%)$ respondents disagreed; while 6 $(7.1 \%)$ respondents strongly disagreed. The result also showed that $33(38.8 \%)$ respondents strongly agreed that a standard handover process improves nurses' performance in patients care; 31 (36.5\%) respondents agreed; $10(11.8 \%)$ respondents disagreed; while the remaining $11(12.9 \%)$ respondents strongly disagreed. 34 (40.0\%) respondents strongly agreed that handover can be used as a tool for improving communication in nursing care; 28 (32.9\%) respondents agreed; 13 (15.3\%) respondents disagreed; while the remaining 10 $(11.8 \%)$ respondents strongly disagreed.

\begin{tabular}{|c|c|c|c|c|c|c|}
\hline \multirow{2}{*}{ Statement } & \multicolumn{5}{|c|}{ Responses } & \multirow{2}{*}{ Total } \\
\cline { 2 - 7 } & & SA & A & D & SD & \\
\hline $\begin{array}{c}\text { Nurse handover enhances transfer } \\
\text { of patients information from one } \\
\text { shift to another }\end{array}$ & Freq & 71 & 14 & - & - & 85 \\
\cline { 2 - 8 } & $\%$ & 82.8 & 16.4 & & & 100 \\
\hline $\begin{array}{c}\text { Handover enhance nurses' and } \\
\text { patients family relationship }\end{array}$ & Freq & 10 & 2 & 33 & 38 & 85 \\
\cline { 2 - 8 } & $\%$ & 11.8 & 2.4 & 38.8 & 44.7 & 100.0 \\
\hline $\begin{array}{c}\text { Handover helps nurses to improve } \\
\text { patients safety }\end{array}$ & Freq & 39 & 36 & 4 & 6 & 85 \\
\cline { 2 - 8 } & $\%$ & 45.9 & 42.4 & 4.7 & 7.1 & 100.0 \\
\hline $\begin{array}{c}\text { Through handover nurses' are able } \\
\text { to improve their clinical outcomes }\end{array}$ & Freq & 42 & 32 & 5 & 6 & 85 \\
\hline \multirow{2}{*}{$\begin{array}{c}\text { A standard handover process } \\
\text { improves nurses performance in } \\
\text { patients care }\end{array}$} & Freq & 33 & 31 & 10 & 11 & 85 \\
\cline { 2 - 8 } & $\%$ & 38.8 & 36.5 & 10 & 12.9 & 100.0 \\
\hline $\begin{array}{c}\text { Handover can be used as a tool } \\
\text { for improving communication in } \\
\text { nursing care }\end{array}$ & Freq & 34 & 28 & 13 & 10 & 85 \\
\cline { 2 - 7 } & $\%$ & 40.0 & 32.9 & 15.3 & 11.8 & 100.0 \\
\hline
\end{tabular}

Table 5: Showing Implication of Nurse handover on patients care. (Positive $=$ summation of strongly agree SA \& Agree A, Negative = summation of Disagree D \& Strongly disagree SA).

\section{Null Hypothesis}

There is no significant relationship between nurse handover and patients care in University of Calabar Teaching Hospital, Calabar.

Result reveals that the calculated $r=$ value of 0.195 is far higher than the critical value of 0.165 at 0.05 level of significance. Hence the null hypothesis is rejected. This implies that there is a significant positive relationship between nurse handover and patients care (Table 6).

\begin{tabular}{|c|c|c|c|c|c|c|}
\hline Variables & $\begin{array}{c}\sum \mathbf{x} \\
\sum \mathbf{y}\end{array}$ & $\begin{array}{c}\sum \mathbf{x}^{\mathbf{2}} \\
\sum \mathbf{y}^{\mathbf{2}}\end{array}$ & $\sum \mathbf{X Y}$ & $\mathbf{d f}$ & r-value & $\begin{array}{c}\text { Sig } \\
\text { r-critical }\end{array}$ \\
\hline Nurse handover (x) & 2579 & 4679 & & & & \\
\hline Patients care (Y) & 2376 & 4585 & 67233 & 148 & 0.195 & 0.165 \\
\hline
\end{tabular}

Table 6: Pearson's product moment correlation Analysis showing the relationship between Nurse Handover and patients care $\mathrm{N}=85$.

\section{Discussion of findings}

This study which examined nurses handover and its implication for nursing care in University of Calabar Teaching Hospital (UCTH), Calabar, identified report writing and bedside verbal handover, as the main methods of nurse handover practiced in
UCTH , compound report, clinical meetings, and medication and observation chart were rarely practiced. However, the study highlighted that audiotape recording as a method of nurses handover is not practiced in UCTH. The study also revealed that transfer of information from one shift to the other is an important aspect of nurse handover and that report writing gives details of the health condition of each patients in the handover process, while recognizing that Nursing care plan is a critical aspect of nurses handover, as it highlights patients' problems, nurses' plan of care and interventions within each shift as well as the outcome of care, and this directs and guides the patient care for the next shift. These findings corroborates the findings of various studies which revealed that handover is very significant to nursing practice as it offers nurses opportunity to weigh the benefit and responsibilities of sharing the information that is in their hands with others [4,1114]. Accordingly, as defenders of patient and professional privacy, nursing professionals should be clear on the intentions of sharing facts and opinions and, similarly, determining the manner of management of relevant, confidential information for the patient's care. On the other hand, there was a strong contention that though bedside verbal nurse handover helps the nurses to exchange relevant information about patients care, it does not permit sharing of vital information concerning the patients' condition. This view might be as a result of the fear that completing the shift report with patients may lengthen rather than shorten the time in the event of asking questions due to interaction with them and family. This findings contrast the findings of the study by [20] which revealed that the sharing of information between shifts is encouraged through bedside verbal nurse handover as there is the patient's direct observation of both nurses rather than generating assumptions, hence when the report is not completed with the patient, the opportunity to include the patient and family in planning care is lost [20]. Accordingly, study by [21] demonstrate the benefits of this process to include the nurse's ability to confirm the information immediately by viewing the patient and obtaining a baseline assessment to compare changes during the shift, thus planning and prioritizing the patient's care [21].

On factors influencing nurse handover in the UCTH, findings revealed that communication is a vital element in the handover process, handover process depends on the type of information available to the incoming nurse that is report content, the attitude of the nurses' can influence the effectiveness of nurses handover, ethics of handover serve as fundamentals to meet patient safety challenges, lateness to work, workload and stress, as well as interpersonal conflicts among staff. This is where the formal training of nurse handover, its importance and processes come to play. Accordingly as noted by [11], that the nurse handover is not taught formally during training, yet it is one of the most important rituals of the nursing shifts. However, majority of respondents never viewed the nurses' experience as an important factor in the handover process. These findings are in line with findings of studies by $[2,16-18,23)$, that the transfer of essential information and responsibility for care of the patient from one nurse on duty to another is an integral component of communication system in nursing care practice. This procedure in nursing care practice 
supports the transition of critical information and continuity of care and treatment. Also in support, study by [24], concluded that awareness of professional handing over ethics and its contributing factors could help nurses and healthcare professionals provide better services for patients.

Findings from the study revealed that nurse handover has a great implication on patient care. As highlighted by respondents, these implications include; nurse handover helps nurses to improve patients' safety, improve their clinical outcomes, improves nurses' performance in patient care, and can be used as a tool for improving communication in nursing care. These findings are in consonance with findings from various studies by $[2,5,12,18,25-27]$, which revealed that through the nurse handover process, information about the patients' physical, psychosocial, and spiritual aspects, as well as medical facts, opinions, and impressions, are shared to resolve care problems, to give and receive help, to construct relationships, and to manage conflicts. However, majority of the respondents were of the opinion that nurse handover does not enhance nurses' and patients/ family relationship. This is in consonance with the view of [19], which stated that nursing professionals do not realize that the patients and their families are administrators of their own care in a hospital stay, and they are not given the opportunity to listen to and participate in the exchange of information.

Hence, the author concluded that nurse handover should be sufficiently broad to be holistic in nature and to consider the patient's long-term care objectives, but it should also be sufficiently specific to meet short-term goals and to offer individual preferences for satisfying the patient's needs and not the needs of the nursing professionals [19].

Testing of the null hypothesis which stated that, there is no significant relationship between Nurses handover and patients care in University of Calabar Teaching Hospital (UCTH) Calabar, revealed a significant positive relationship between nurse handover and patients care. This finding is in line with the findings of [2,7] which emphasis that the nurse handover should be informative and educative for the nurses, patients, and their families, and should convey not only details about the patient's state and treatment but also care plans to ensure patients' care and safety. Also in support is the finding by [11] that patients who are better informed are less anxious, more adherent to their care, more autonomous in their treatment and goals, and feel satisfied. Additionally, healthcare costs are reduced by the self-management performed by patients and the more efficient use of resources. Furthermore, [6], noted that the benefits of carrying out the handover with the patient include not only taking the patient into consideration with a more holistic and prioritized care, but also greater professional satisfaction, which encourages teamwork across all shifts, promoting personal responsibility and universal commitment is enhanced.

\section{Conclusion and Recommendation}

The study concluded that the nurse handover process is characterized as being a routine, daily event that is performed in all the shifts, and is a key moment for guaranteeing the continuity of care and the patients' safety. The benefits include not only taking the patient into consideration with a more holistic and prioritized care but also enhances greater professional satisfaction, which encourages teamwork across all shifts, promote personal responsibility and universal commitment. Thus the following recommended were made based on the findings;

- Nurse handover should be made part of the training curriculum for student nurses in order to improve knowledge

- There is need for regular updates among nurses to enable them acquire special skills that will enhance better communication during handover

- Nurses' should ensure a standard handover process in order improve nurses performance in patients care,

- Nurses should ensure proper handover process as a tool to enhance nurses' and patients family relationship

- There is need for nurses to ensure adequate transfer of information from one shift to the other through comprehensive and appropriate report content, in order to make the handover process effective.

\section{References}

1. Radtke K. Improving patient satisfaction with nursing communication using bedside shift report. Clin Nurse Spec. 2013; 27:19-25.

2. Griffin T. Bringing change-of-shift report to the bedside: A patient- and family-centered approach. The Journal of Perinatal \& Neonatal Nursing. 2010; 24: 348-353.

3. Spanke MT, Thomas T. Nursing assistant walking report at change of shift. Journal of nurse care quality. 2010; 25: 261265.

4. White L, Duncan G, Baumle W. Foundations of Basic Nursing practice. Third Edition ed. 2011; USA NY: Delmar Cengage Learning.

5. Haniha A. Communication in Verbal Hand-Over Reports: Nurses' Experiences from In-Patients Hospital Units in Saudi Arabia. Middle East Journal of Nursing. 2013; 7.

6. Baker SJ. Bedside shift report improves patient safety and nurse accountability. Journal of Emergency Nursing. 2010; 36: 355-358.

7. Gordon M, Findley R. Educational interventions to improve handover in health care: A systematic review. Medical Education. 2011; 45: 1081-1089.

8. Tanja M. Effective handover communication: An overview of research and improvement efforts. Best Practice \& Research Clinical. 2011; 2: 181-191.

9. Blouin AS. Improving hand-off communications: New solutions for nurses. Journal of Nursing Care Quality. 2011; 26: 97-100.

10. Mott S, Bradley S. Transforming care: An investigation of the introduction of bedside handover to three rural hospitals. 2010.

11. Scovell S. Role of the nurse-to-nurse handover in patient care. Nursing Standard. 2011; 24: 35-39.

12. Scott I. Clinical handover: do we need it? What are the implications of not having it? 2012.

13. Mayor E, Bangerter A, Aribot M. Task uncertainty and 
communication during nursing shift handovers [Evaluation Studies Research Support, non-U.S. Gov't]. Journal of Advanced Nursing. 2012; 68: 1956-1966.

14. Johnson M, Cowin LS. Nurses discuss bedside handover and using written handover. Journal of nursing management. 2012; 10: 1365-2834.

15. http://www.health.qld.gov.au/psq/handover/docs/ch presentation2.pdf

16. McMurray A, Chaboyer W, Wallis M, Johnson, J, Gehrke T. Patients' perspectives of bedside nursing handover [Research Support, non-U.S.] Gov’t.Collegian.2011; 18: 19-26.

17. Sles S. Role of the nurse-to-nurse handover in patient care. Nursing Standard. 2010; 24: 35-39.

18. Rahele S, Marzieh M, Alireza N, et al. Challenges of Nursing Handover: A Qualitative Study. Clinical Nursing Research. 2015; 24: 234-252.

19. Riesenberg LA, Leitzsch J, Cunningham JM. Nursing handoffs: a systematic review of the literature. Am J Nurs. 2010; 110: 24-34.

20. Welsh CA, Flanagan ME, Ebright P. Barriers and facilitators to nursing handoffs: Recommendations for redesign. Nursing Outlook. 2010; 58: 148-154.
21. White L, Duncan G, Baumle W. Foundations of Basic Nursing practice. Third Edition ed. 2011; USA NY: Delmar Cengage Learning.

22. Javad, Seyed, Tokam, Alireza. A Standardized Shift Handover Protocol: Improving Nurses' Safe Practice in Intensive Care Unit. J Caring Sci. 2013; 2: 177-185.

23. Siemsen MD, Andersen HB, Ostergaard D. Factors that impact on the safety of patient handovers: An interview study. Scandinavian Journal of Public Health. 2012; 40: 439-448.

24. Denghan A, Leili M, Denghan-Nayaeri N. Factors affecting professional ethics in nursing practice in Iran: a qualitative study. BMC Medical Ethics. 2015; 16: 61.

25. Chung K, Davis I, Moughrabi S. MedSurg. 2011 - Jannetti Publications, Inc.

26. Dufault M, Duquette CE, Ehmann J, et al. Translating an evidence-based protocol for nurse-to-nurse shift handoffs. Worldviews on Evidence-Based Nursing. 2010; 7: 59-75.

27. Jukkala AM, James D, Autrey P, et al. Developing a standardized tool to improve nurse communication during shift report. Journal of nursing care quality. 2012; 27: 240246.

(C) 2018 Alberta Davi N, et al. This article is distributed under the terms of the Creative Commons Attribution 4.0 International License 